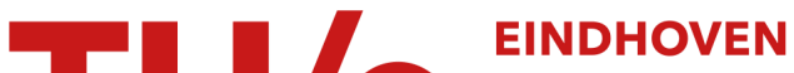 \\ UNIVERSITY OF \\ TECHNOLOGY
}

\section{How important is Moessbauer spectroscopy in catalysis?}

Citation for published version (APA):

Niemantsverdriet, J. W. (1989). How important is Moessbauer spectroscopy in catalysis? Hyperfine Interactions, 47-48(1-4), 219-235. https://doi.org/10.1007/BF02351609

DOI:

10.1007/BF02351609

Document status and date:

Published: 01/01/1989

\section{Document Version:}

Publisher's PDF, also known as Version of Record (includes final page, issue and volume numbers)

\section{Please check the document version of this publication:}

- A submitted manuscript is the version of the article upon submission and before peer-review. There can be important differences between the submitted version and the official published version of record. People interested in the research are advised to contact the author for the final version of the publication, or visit the $\mathrm{DOI}$ to the publisher's website.

- The final author version and the galley proof are versions of the publication after peer review.

- The final published version features the final layout of the paper including the volume, issue and page numbers.

Link to publication

\section{General rights}

Copyright and moral rights for the publications made accessible in the public portal are retained by the authors and/or other copyright owners and it is a condition of accessing publications that users recognise and abide by the legal requirements associated with these rights.

- Users may download and print one copy of any publication from the public portal for the purpose of private study or research.

- You may not further distribute the material or use it for any profit-making activity or commercial gain

- You may freely distribute the URL identifying the publication in the public portal.

If the publication is distributed under the terms of Article 25fa of the Dutch Copyright Act, indicated by the "Taverne" license above, please follow below link for the End User Agreement:

www.tue.nl/taverne

Take down policy

If you believe that this document breaches copyright please contact us at:

openaccess@tue.nl

providing details and we will investigate your claim. 


\title{
HOW IMPORTANT IS MÖSSBAUER SPECTROSCOPY IN CATALYSIS?
}

\author{
J.W. NIEMANTSVERDRIET
}

Laboratory of Inorganic Chemistry and Catalysis, Eindhoven University of Technology, NL-5600 MB Eindhoven, The Netherlands

\begin{abstract}
Applications of Mössbauer spectroscopy in catalysis are reviewed with the emphasis on the typc of information obtained and the performance of Mössbauer spectroscopy in comparison to other techniques. Statistical data are presented to show how often the various spectroscopies are used in catalysis. Finally, the importance of Mössbauer spectroscopy in catalysis is discussed.
\end{abstract}

\section{Introduction}

During the last two decades, Mössbauer spectroscopy has become a generally accepted technique in catalysis. It has, for example, contributed significantly to the current understanding of catalysts used in ammonia synthesis, hydrotreating and $\mathrm{CO}$ hydrogenation. Reviews of the application of Mössbauer spectroscopy on specific catalysts can be found in references [1-3]. The purpose of this paper is to review briefly the capabilities and merits of Mössbauer spectroscopy in relation to other techniques which are frequently used in catalysis, and to answer the question in the title of this paper.

\section{What is catalysis?}

A reaction between gases catalyzed by a solid begins with the adsorption of the reactants on the surface of the catalyst. The next step is the reaction on the surface, often in several consecutive steps. Finally, the products desorb from the surface into the gas phase. The function of the catalyst is to provide an energetically favorable pathway for the overall reaction, in which activation barriers of all intermediate steps are low compared to the activation energy of the gas phase reaction.

Catalysis takes place at the surface of the catalyst. Hence, a catalyst should preferably consist of small particles, with a high fraction of surface atoms. Often, this is achieved by dispersing particles on a chemically inert, porous support such as 
$\mathrm{SiO}_{2}, \mathrm{Al}_{2} \mathrm{O}_{3}, \mathrm{TiO}_{2}$, or carbon. (N.B. Unsupported catalysts are also used, for example the iron ammonia synthesis catalyst.) Figure 1 shows an impression of a supported metal catalyst.

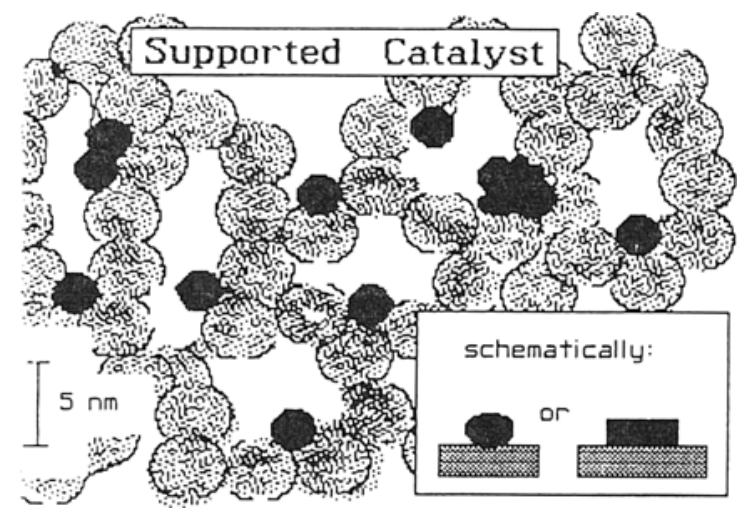

Fig. 1. Model of a silica-supported catalyst; the inset show's the usual schematic representation.

Supported catalysts are usually prepared by impregnating the support with a solution of a metal salt (for example, iron nitrate in water). The quantity of solution should be just sufficient to fill the pores such that no metal salt will end up outside the support, where it will eventually agglomerate. After impregnation, the system is carefully dried and finally reduced in $\mathrm{H}_{2}$ to obtain metal particles.

\section{Aim of catalyst characterization}

Nowadays, it is believed that catalytic properties of a surface are determined by its composition and structure on the atomic scale. Thus, it is not sufficient to know that a surface consists of a metal and a promoter, say iron and potassium, but it is essential to know the exact structure of the iron surface, including defects, steps, etc., as well as the exact location of the promoter atoms. Thus, from a fundamental point of view, the ultimate goal of catalyst characterization should be to look at the surface atom by atom, under reaction conditions. At present, however, no technique or combination of techniques can achieve this.

In principle, two approaches are used to investigate relations between catalytic properties and catalyst composition and structure. First, studies in which the catalytic surface is that of a single crystal or a needle-shaped tip, as used in field ion microscopy [4]. With the appropriate combination of surface spectroscopies, the desired characterization on the atomic scale is certainly possible in favorable cases. The disadvantage, however, is that although one can study the catalytic properties of such 
samples under realistic conditions (pressures of 1 atm or higher), most of the characterization is necessarily carried out in ultra-high vacuum, and not under reaction conditions.

The second approach is to study real catalysts with in situ techniques such as Mössbauer spectroscopy, EXAFS and XRD, under reaction conditions, or, as is more often done, under controlled environment after quenching of the reaction. The in situ techniques, however, are not sufficiently surface specific to yield the desired atom by atom characterization of the surface. At best, they determine the composition of the particles.

It is good to realize that, although many techniques undoubtedly reveal usable information on catalysts, the information desirable from a fundamental point of view cannot be obtained. In this situation, it is a good strategy to combine all techniques which have something to say about the catalyst. The catalysis literature contains several examples where this approach has been remarkably successful.

\section{Mössbauer spectroscopy in catalyst characterization}

Most applications of Mössbauer spectroscopy to catalysts fall in one of the five categories listed in table 1. Each category will be illustrated with examples from our work on supported iron and iron alloy catalysts.

Table 1

Applications of Mössbauer spectroscopy in catalyst characterization, together with frequently used alternative techniques

\begin{tabular}{ll}
\hline \multicolumn{1}{c}{ Category } & \multicolumn{1}{c}{ Alternative } \\
\hline (a) phase identification & XRD \\
(b) determination of oxidation state & XPS \\
(c) structure information & EXAFS \\
(d) particle size determination & XRD EM chemisorption \\
(c) kinetics of bulk transformations & gravimetric magnetic \\
\hline
\end{tabular}

(a)

\section{PHASE IDENTIFICATION}

An example of how Mössbauer spectroscopy is used in the identification of phases in supported iron catalysts is given in fig. 2. The top spectrum belongs to a fresh $\mathrm{Fe} / \mathrm{TiO}_{2}$ catalysts, i.e. after impregnation and drying. The spectrum shows that iron is present in the ferric state, probably as small particles or a dispersed layer of an oxide or oxyhydroxide. After reduction in $\mathrm{H}_{2}$ at $675 \mathrm{~K}$, the catalyst consists mainly of metallic iron, as evidenced by the sextet in the corresponding spectrum of fig. 2 , 


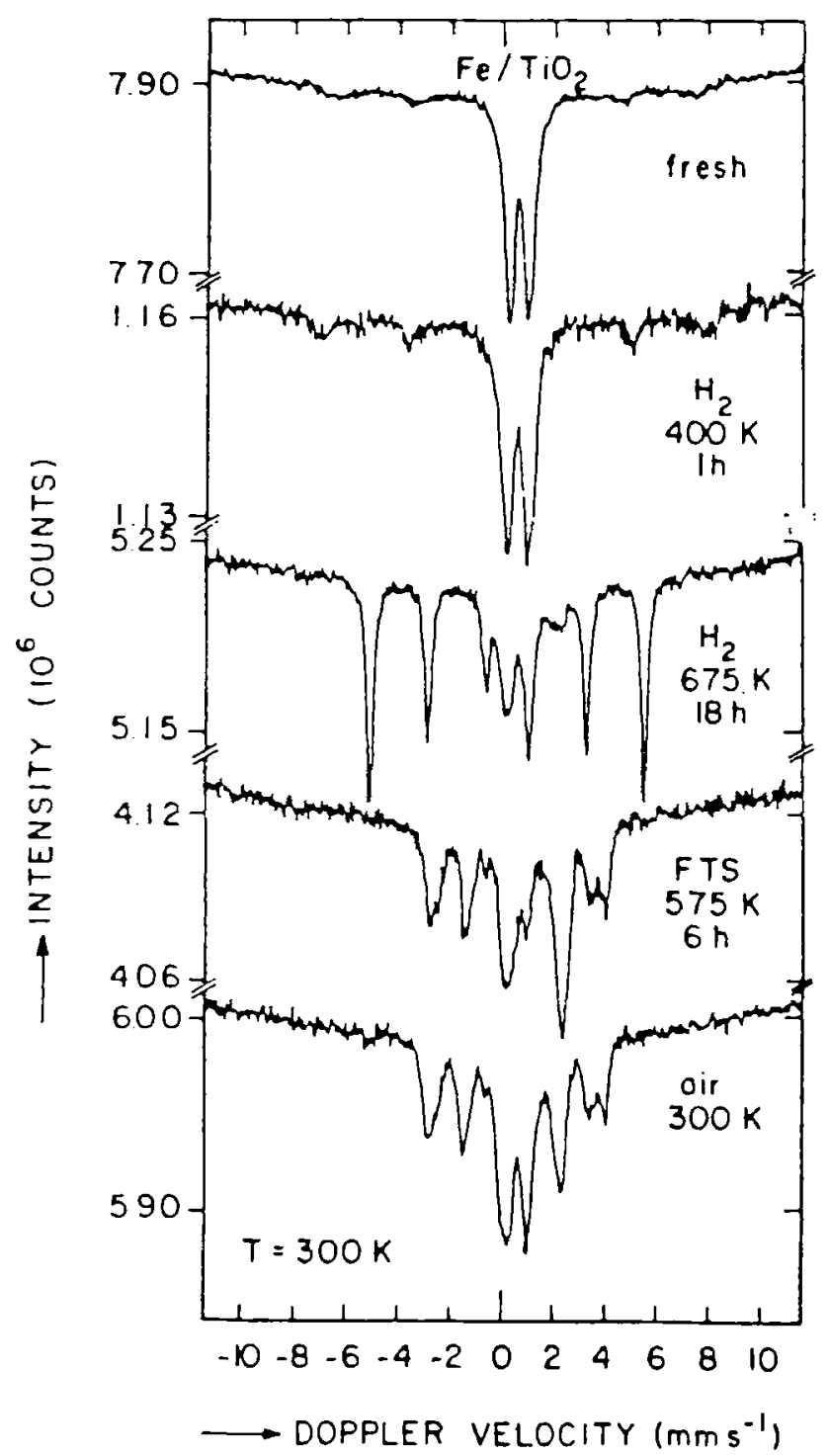

Fig. 2. Mössbauer spectra at room temperature give detailed information on the state of iron in a $\mathrm{TiO}_{2}$ supported iron catalyst after different treatments. $\mathrm{H}_{2}, 675 \mathrm{~K}, 18 \mathrm{~h}$ stands for $18 \mathrm{~h}$ reduction at $675 \mathrm{~K}$. FTS for Fischer-Tropsch synthesis, air for exposure of the spent catalyst to the air at $295 \mathrm{~K}$. Reproduced with permission from Applied Catalysis [5]. 
along with some unreduced iron, which gives rise to two doublet contributions of $\mathrm{Fe}^{2+}$ and $\mathrm{Fe}^{3+}$. However, the overall degree of iron reduction, as reflected by the relative area under the bcc-iron sextet, is high. Fischer-Tropsch synthesis at $575 \mathrm{~K}$ in $\mathrm{CO}$ and $\mathrm{H}_{2}$ converts the metallic iron to the Hägg carbide $\chi-\mathrm{Fe}_{5} \mathrm{C}_{2}$. Almost all unreduced iron is now present as $\mathrm{Fe}^{2+}$. Exposure of the carburized catalyst to air at room temperature leaves most of the carbide phase unaltered, but oxidizes the ferrous to ferric iron. A detailed discussion of these spectra is given in ref. [5].

This example illustrates how Mössbauer spectroscopy reveals the identity of the major iron phases in a supported catalyst after different treatments. The example is typical for many applications of Mössbauer spectroscopy in catalysis: a catalyst undergoes a certain treatment; next, its Mössbauer spectrum is measured in situ at room temperature.

A complete characterization of phases in a catalyst sometimes requires that spectra are measured in situ at cryogenic temperatures, in particular when phases are superparamagnetic at room temperature. An example is given in fig. 3 . The $295 \mathrm{~K}$ spectrum of a carbon-supported iron catalyst after reduction in $\mathrm{H}_{2}$ shows a large and poorly resolved contribution in the central region of the spectrum, along with traces of the $\alpha-\mathrm{Fe}$ sextet. An unambiguous interpretation of this spectrum alone is almost impossible. The same sample at $77 \mathrm{~K}$ gives a much better resolved spectrum, but does not clarify whether the single peak in the middle of the spectrum belongs to superparamagnetic $\alpha$-Fe or some iron-carbide, for example formed from a reaction between the support and the iron on top. The liquid helium spectrum provides a clear answer: the majority of the iron gives rise to a sextet with a magnetic hyperfine field of $345 \mathrm{kOe}$, and is due to $\alpha-\mathrm{Fe}$. Note that the splitting is about $7 \mathrm{kOe}$ higher than in bulk $\alpha$-Fe, in agreement with the demagnetizing field of spherical, single domain particles. Details about the interesting magnetism of the $\mathrm{Fe} / \mathrm{C}$ system are given in [6] The reader is referred to Mørup et al. [7] for a general introduction to the magnetism of small particles. The work on the carbon-supported iron illustrates how useful in situ Mössbauer spectra at temperatures down to $4 \mathrm{~K}$ can be in studying small particles.

The two examples discussed so far deal with the identification of phases only. Concentrations of the iron constituents can be derived if the respective recoilless fractions are known. These can be calculated if spectra are measured at different temperatures, e.g. 300,77 and $4 \mathrm{~K}$, with the sample in the same geometry. When the spectral area of each constituent iron phase is fitted with the Debye model as a function of temperature, the Debye temperature of each phase is obtained. Next, the recoilless fractions can be calculated at any desired temperature [8] .

Probably the most common technique to identify phases in materials science is X-ray diffraction. However, as the small particles used in catalysts may by X-ray amorphous and, moreover, surface layers are invisible for XRD, this technique, al though widely used, is actually of limited use for the study of catalysts. The advantage of 


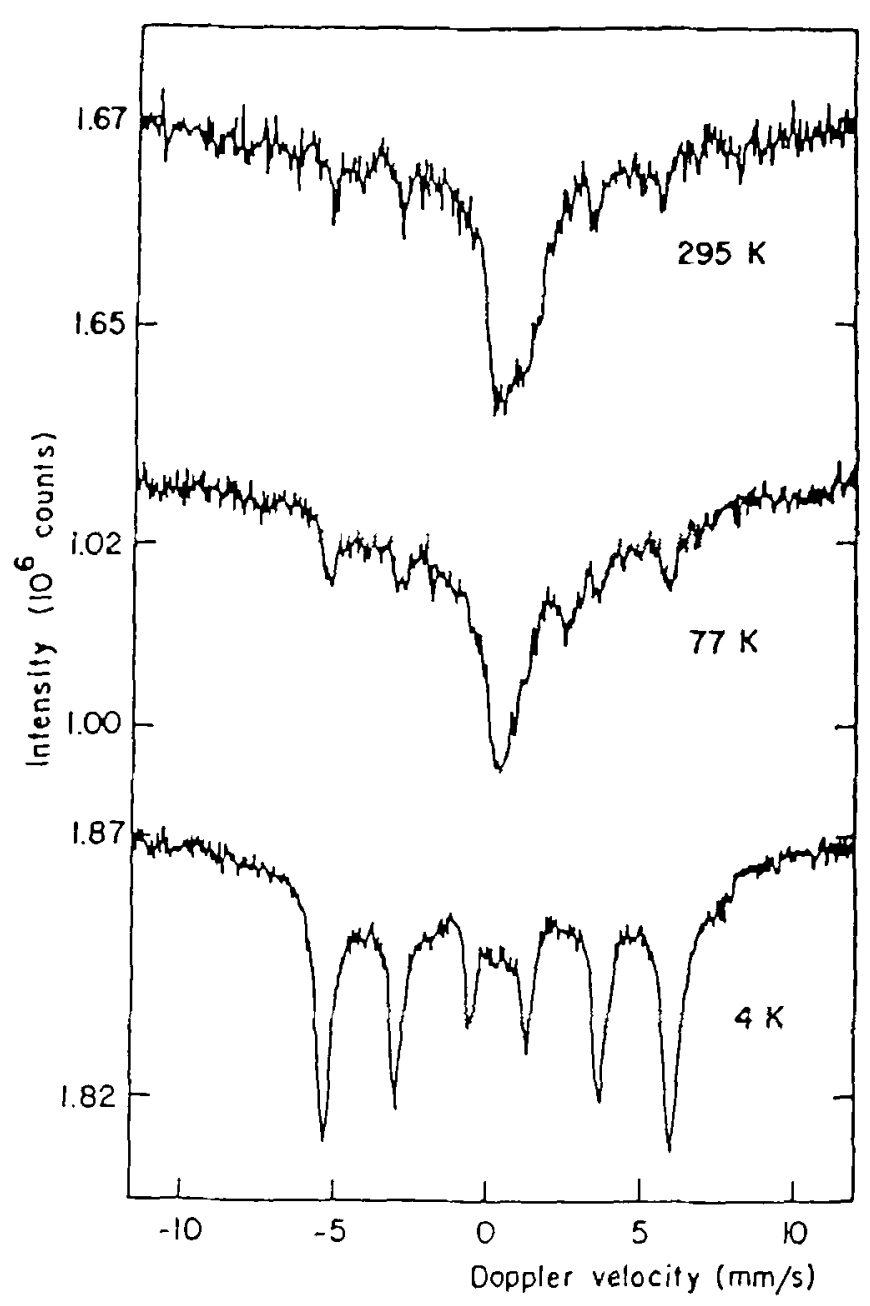

IFig. 3. Mössbauer spectra of a carbon-supported iron catalyst after reduction in $\mathrm{H}_{2}$ at $740 \mathrm{~K}$, measured in situ at 295,77 and $4 \mathrm{~K}$. The liquid helium spectrum shows the sextet of metallic iron and confirms that the spectra at 77 and $295 \mathrm{~K}$ contain contributions from superparamagnetic metallic iron. Reproduced with permission from the Journal of Physical Chemistry [6].

Mössbauer spectroscopy in the identification of phases is that it detects snall particles and amorphous phases, and that the surface contributes to the spectrum, be it often with a lower recoilless fraction. 
Catalysts often have such high dispersions that one cannot speak of welldefined phases with a unique structure. All one actually determines in such cases is the oxidation state. An example has been met above. The spectra of reduced $\mathrm{Fe} / \mathrm{TiO}_{2}$ contained two doublets of $\mathrm{Fe}^{2+}$ and $\mathrm{Fe}^{3+}$, for which a more detailed assignment to a certain compound was not possible.

Another example in which the information from Mössbauer spectroscopy is limited to oxidation states is given in fig. 4 [9]. Here, the course of reduction of a bimetallic FeIr catalyst has been followed with Mössbauer spectroscopy. The spectra show that the reduction of ferric iron in a fresh $\mathrm{FeIr} / \mathrm{SiO}_{2}$ catalyst to ferrous iron starts already around $375 \mathrm{~K}$, whereas further reduction to iron in the zero valent state takes place at $475 \mathrm{~K}$. Note that the reduction of $\mathrm{Fe}^{2+}$ to $\mathrm{Fe}^{0}$ is accompanied by oxidation of $\mathrm{Fe}^{2+}$ to $\mathrm{Fe}^{3+}$. This unexpected phenomenon has been observed in several other highly dispersed bimetallic catalysts [5.10]. It probably reflects the formation of an interface compound between iron and the $\mathrm{SiO}_{2}$ support, possibly under the influence of hydroxyl groups. However, the reducible fraction of the iron in the FeIr catalyst reduces at temperatures which are $150-200 \mathrm{~K}$ lower than those necessary for the reduction of monometallic iron catalysts. Promotion of the reduction of iron by noble metals has been observed in many bimetallic systems; it is already effective when the noble metal is present in trace amounts [11].

The most frequently used technique for the determination of oxidation states is X-ray Photoelectron Spectroscopy (XPS), an ultra-high vacuum technique. In comparison to XPS, Mössbauer spectroscopy has the advantage that it does not require vacuum but can be applied in situ. As the oxidation state of iron in highly dispersed bimetallic catalysts may vary with the gas environment (fig. 5), this is an important feature!

\section{STRUCTURE INIORMATION}

Incidentally, Mössbauer spectroscopy provides useful information about the structure of a catalyst. Exposing the catalyst to a strongly adsorbing gas and monitoring the consequent changes in the Mössbauer spectra may be a way to recognize surface phases [12]. Figure 5 shows that the $\mathrm{Fe}^{3+}$ (the doublet in the top spectrum) present in a reduced $\mathrm{FeRh} / \mathrm{SiO}_{2}$ catalyst is almost entirely converted to $\mathrm{Fe}^{2+}$ after exposure of the sample to $\mathrm{CO}$ at $295 \mathrm{~K}$. The fact that this transformation takes place at room temperature indicates that the converted $\mathrm{Fe}^{3+}$ is accessible for gases and forms a phase of high dispersion. Systematic observations of this kind have led to a rather detailed insight into the structure of supported bimetallic catalysts [10] .

Lattice vibrations may also reveal information which is related to the structure of a catalyst. In the $\mathrm{FeRh} / \mathrm{SiO}_{2}$ catalysts mentioned above, the highly dispersed oxide appeared to have a low Debye temperature of about $175 \mathrm{~K}$. The FeRh alloy, however, 


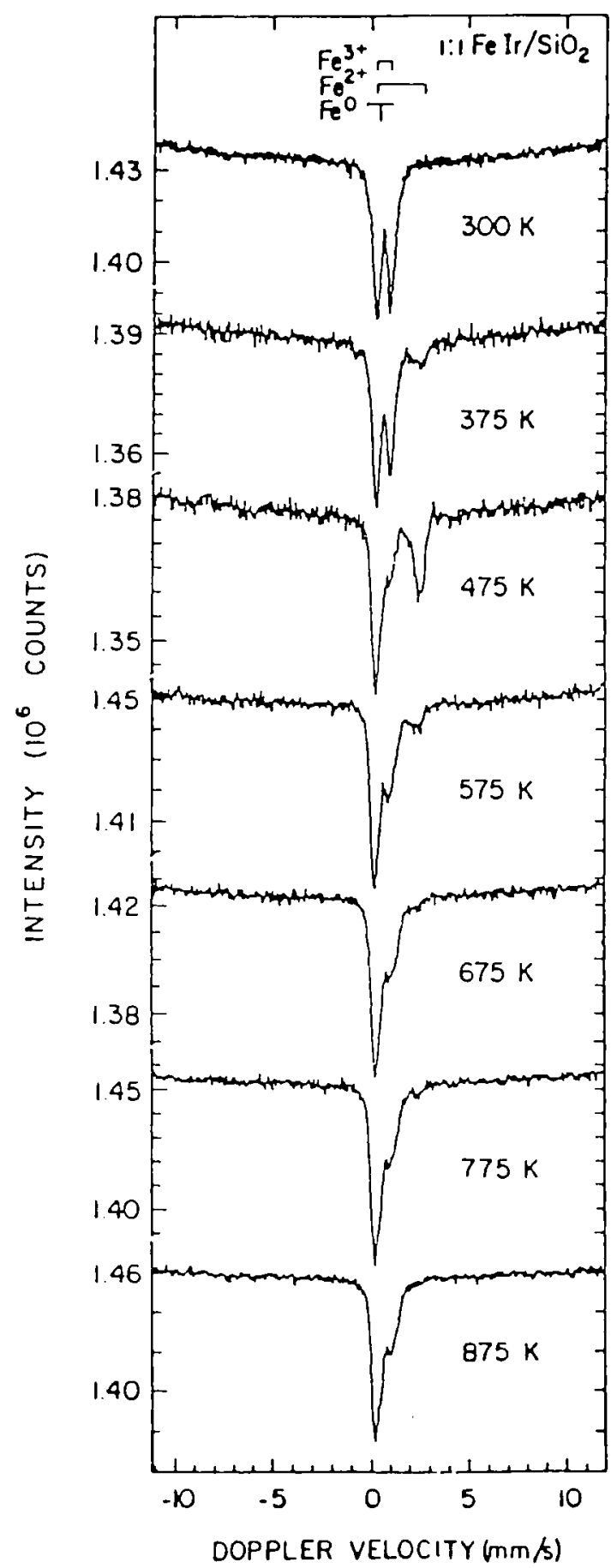

Fig. 4. Mössbauer spectra at room temperature of a bimetallic $\mathrm{Fe}$ - $/ \mathrm{SiO}{ }_{2}$ catalyst after treatment in $\mathrm{H}_{2}$ at the indicated temperatures. Although assignment of the doublets to a certain iron phase is not possible, the spectra provide a detailed picture of the reduction process. Owing to the presence of the noble metal Ir, the reduction of the initially present oxidic iron is significantly promoted. Reproduced with permission from Surface and Interface Analysis [9]. 


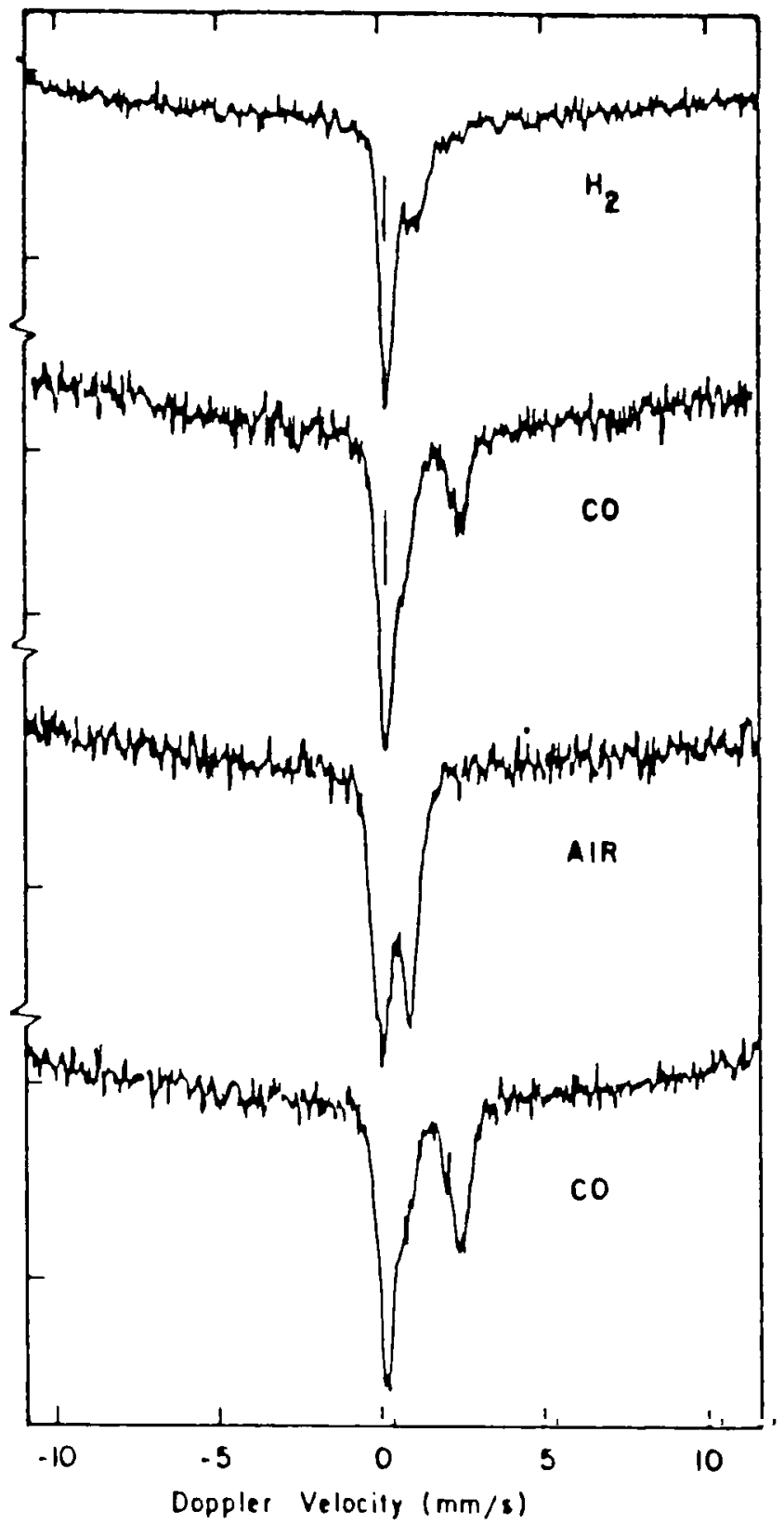

Fig. 5. Mössbauer spectra at $295 \mathrm{~K}$ of an initially reduced $\mathrm{FeRh} / \mathrm{SiO}_{2}$ catalyst under different gases. Note that the $\mathrm{Fe}^{3+}$, visible by the doublet in the spectrum of the catalyst under $\mathrm{H}_{2}$, is almost entirely converted to $\mathrm{Fe}^{2+}$ under the influence of $\mathrm{CO}$ at room temperature. This is considered as evidence that the $\mathrm{Fe}^{3+}$ is present in a highly dispersed phase on the support. Reproduced with permission from the Journal of Molecular Catalysis [12]. 
had a Debye temperature of about $450 \mathrm{~K}$, which is characteristic of bulk behavior. This suggests that the FeRh is present in particles with most of the atoms in the interior [8].

Finally, magnetic hyperfine fields may also contain information on the structure. As described above, the magnetic splitting in spectra of $\alpha$-Fe particles in $\mathrm{Fe} / \mathrm{C}-1$ catalysts measured at $4 \mathrm{~K}$ was about $7 \mathrm{kOe}$ higher than in bulk $\alpha$ - $\mathrm{Fe}$, due to the influence of the demagnetizing field. The latter may vary between 7 and $22 \mathrm{kOe}$, depending on the shape of the particles. The value of $7 \mathrm{kOe}$ observed in the spectra of the $\mathrm{Fe} / \mathrm{C}-1$ catalyst indicates that the $\alpha$-Fe particles are spherically shaped. Furthermore, the fact that the particles are superparamagnetic at low temperatures may be taken as evidence that the particles are magnetically separated from each other, i.e. at a distance that dipole-dipole interactions between their magnetization vectors are unimportant [6].

The examples illustrate that in favorable cases, Mössbauer spectroscopy yields information on the structure. It is difficult to compare the merits of Mössbauer spectroscopy with those of other techniques which also incidentally yield information on the structure of catalysts. The most promising technique in this respect is EXAFS (Extended X-ray Absorption Fine Structure). Clausen discusses a good example of how EXAFS and Mössbauer spectroscopy complement each other in an investigation of hydrotreating catalysts [13].

\section{PARTICLE SIZE DETERMINATION}

When iron particles in catalysts are superparamagnetic, one can determine their size by measuring spectra in externally applied magnetic fields. According to the Langevin equation, a plot of the magnetic hyperfine splitting minus the applied field, versus the reciprocal applied field gives a straight line. The slope of this line contains the volume of the particles.

Figures 6 and 7 show an example of particle-size determination in carbonsupported iron catalysts [14]. The bottom spectra show the singlet of superparamagnetic $\alpha-\mathrm{Fe}$. Application of an external magnetic field induces magnetic hyperfine splitting which increases with the strength of the applied field. The corresponding Langevin plot in fig. 7 yields an intercept of $343 \mathrm{kOe}$, in good agreement with the value of $345 \mathrm{kOe}$ expected for single-domain spherical $\alpha$-Fe particles. The slope of the line corresponds to particles with a diameter of $2.5 \mathrm{~nm}$.

The usual techniques for the determination of particle sizes of catalysts are XRD line-broadening or line profile analysis, electron microscopy, chemisorption, and magnetic measurements. Here, the advantage of Mössbauer spectroscopy is that it simultaneously characterizes the catalyst. As the state of supported iron catalysts depends often on subtleties in the reduction procedure (for example, the type of reactor used), the simultaneous determination of particle size and degree of reduction represents an important advantage of Mössbauer spectroscopy. 


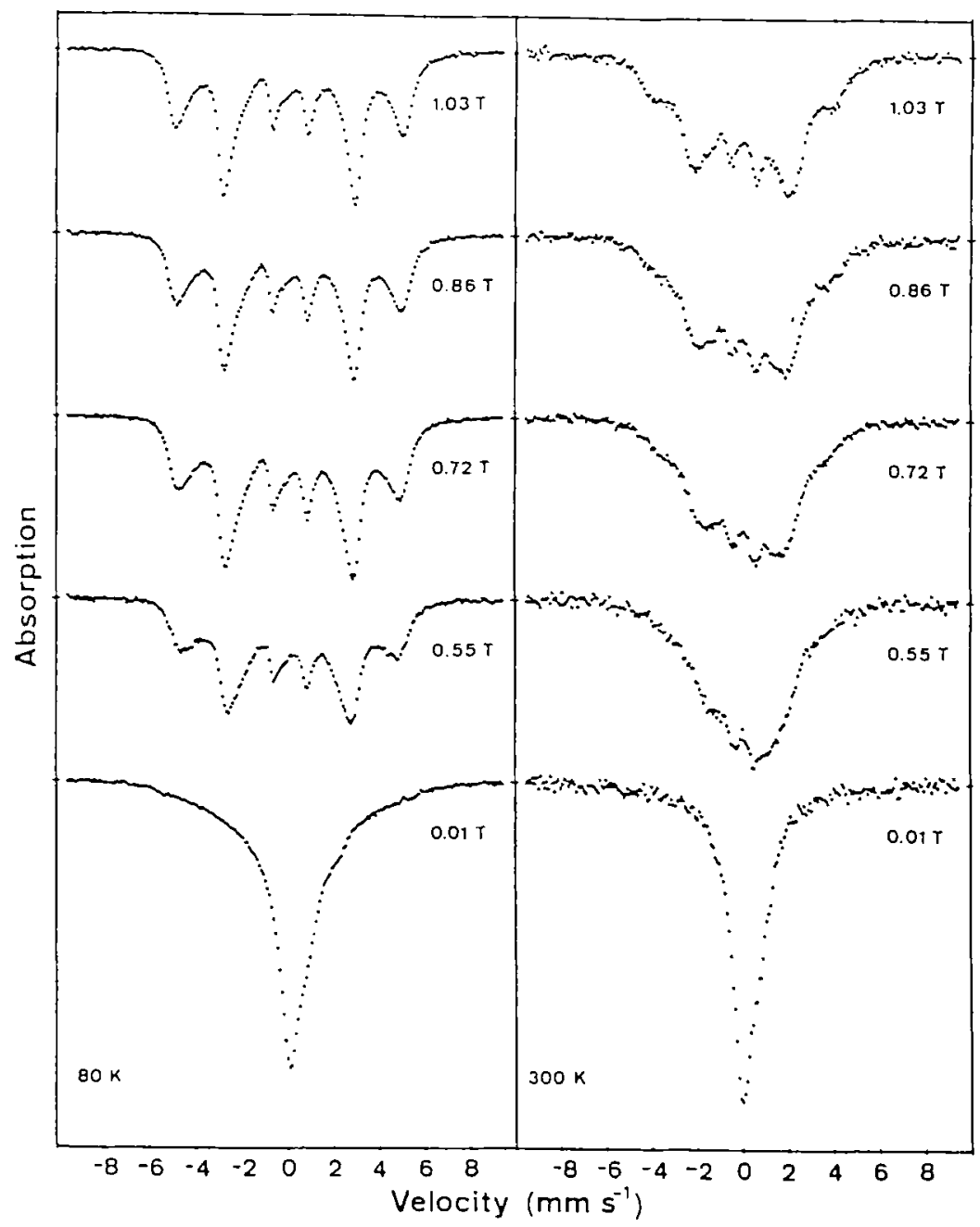

Fig. 6. Mössbauer spectra of a reduced carbon-supported iron catalyst at 80 and $300 \mathrm{~K}$ obtained in different applied magnetic ficlds. The spectra at the bottom, measured without external field, consist predominantly of the singlet of superparamagnetic metallic iron. The application of magnetic ficlds induces magnetic splitting, see also fig. 7. Reproduced with permission from the Journal of Physical Chemistry [14]. 


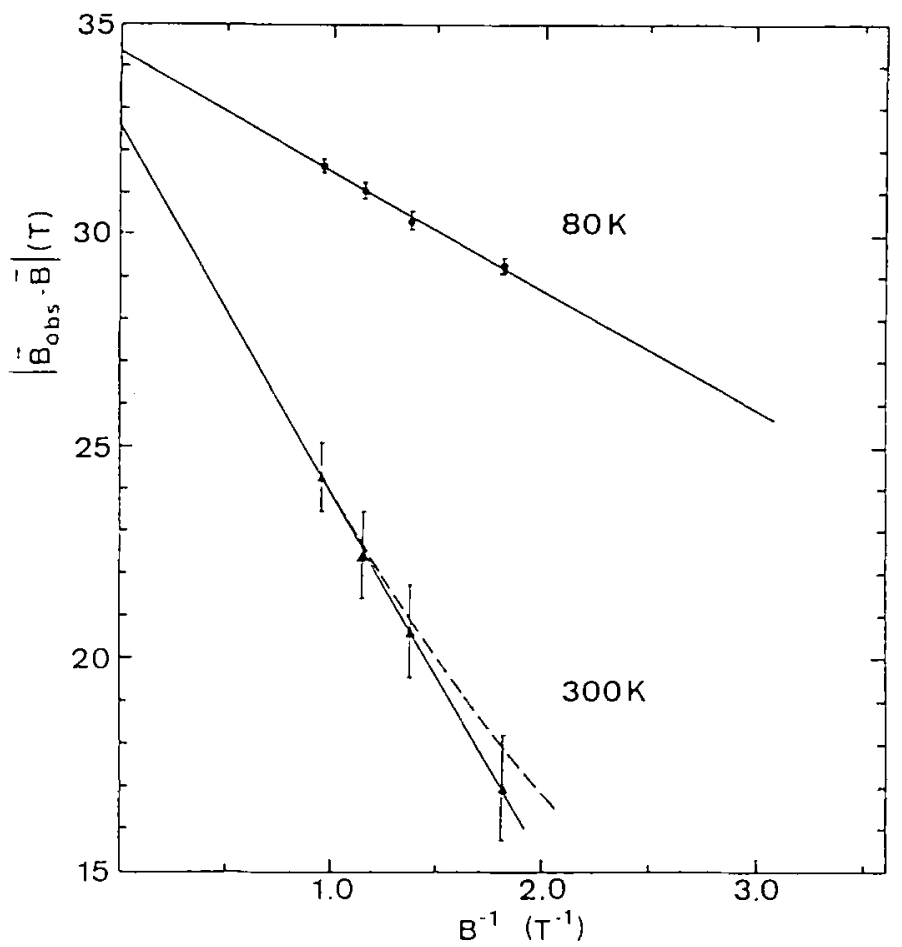

Fig. 7. Langevin plot for the spectra of the carbon-supported iron catalyst in fig. 6 . The curves extrapolate to the magnetic splittings expected for single-domain metallic iron particles. The slopes correspond to a particle diameter of $2.5 \pm 0.2 \mathrm{~nm}$. Rep:oduced with permission from the Journal of Physical Chemistry [14].

(e)

\section{KINETICS OI: BULK TRANSI:ORMATIONS}

The recording of a complete Mössbauer spectrum of an iron catalyst takes typically between several hours and several days. Nevertheless, processes occurring on the time scale of minutes to hours, such as the reduction of iron oxide or the carburization of iron, can be monitored by measuring the intensity of a characteristic peak in the spectrum at constant Doppler velocity. An elegant example has recently been reported by Hummel et al. [15]. The constant velocity spectra in fig. 8 reflect the stability of the nitride $\zeta-\mathrm{Fe}_{2} \mathrm{~N}$ in different atmospheres at $525 \mathrm{~K}$. Common Mössbauer spectra in the constant acceleration mode show that denitridation of $\zeta-\mathrm{Fe}_{2} \mathrm{~N}$ in $\mathrm{H}_{2}$ yields metallic iron. In $\mathrm{CO} / \mathrm{H}_{2}$ mixtures, however, a carbonitride is formed. Constant velocity spectra as in fig. 8 enable one to study the kinetics of these processes. Useful information is obtained by following simultaneously the consumption or evolution of gases involved in the reactions. 


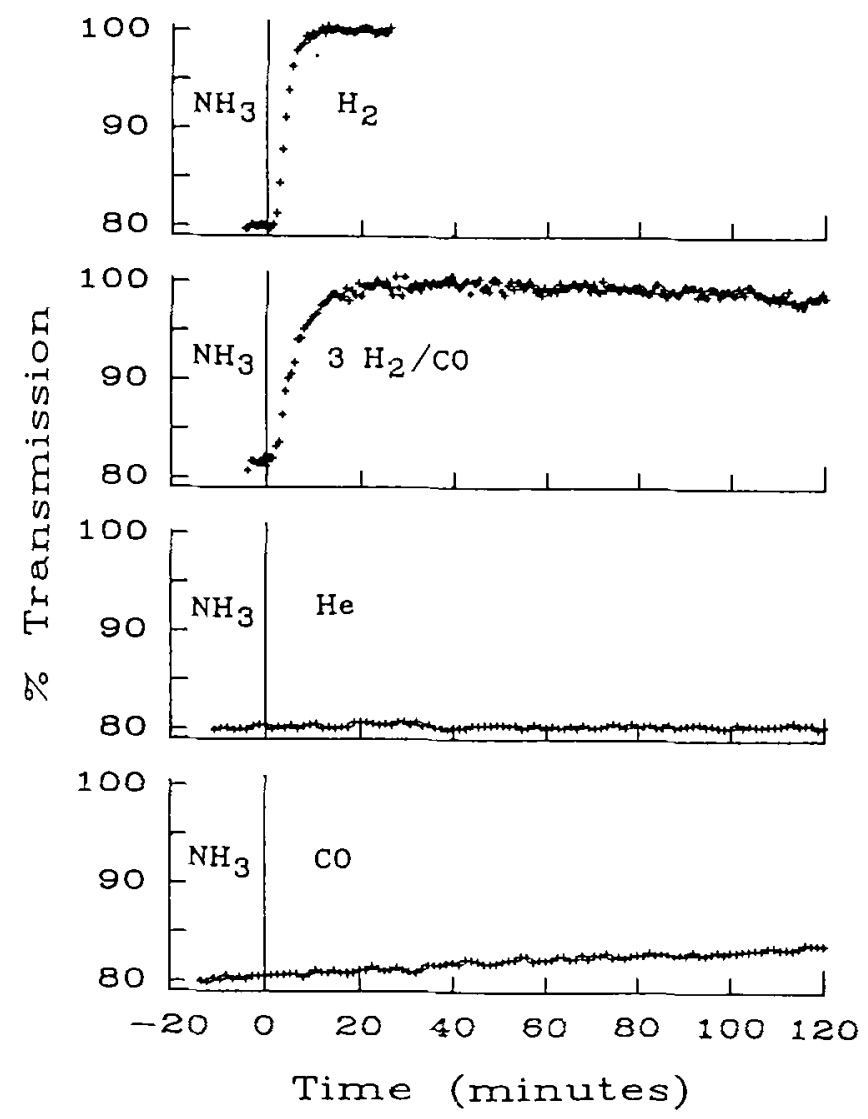

Fig. 8. A constant-vclocity Mössbauer experiment reveals the kinctics of the denitridation of the iron nitride $\zeta-1 \cdot \mathrm{c}_{2} \mathrm{~N}$ in different atmospheres at $525 \mathrm{~K}$. Figure from Humme] et al. [15], reproduced with permission from the Journal of Catalysis.

Alternative ways to study the kinetics of bulk transformations are to monitor changes in weight or magnetism. These methods, however, are less specific about the initial and final state of the catalyst than Mössbauer spectroscopy.

\section{Importance of catalyst characterization}

There are several ways to classify studies in catalysis. Here, we will use three categories: (i) reactions only, (ii) catalyst characterization, and (iii) reactions over characterized catalysts. To obtain insight into the importance of each of these subfields in catalysts, we will count how often each type of investigation was represented at the recently held 9th International Congress on Catalysis (9th ICC) [17]. 


\section{Techmiques used in Catalysis}

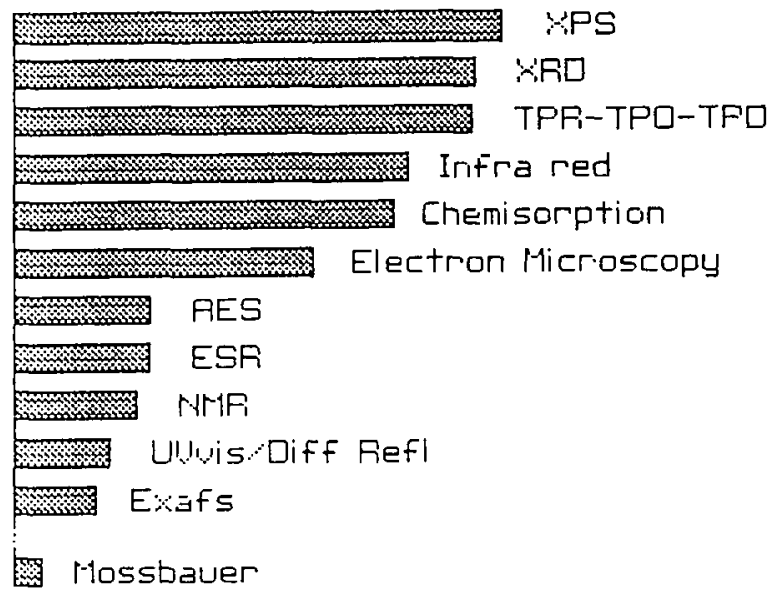

I:ig. 9. Bar diagram showing how often techniques have been used in the about 250 papers presented at the 9 th International Congress on Caltalysis (Calgary, 1988). Mössbauer spectroscopy was used in 4 papers. XPS in 64 . See table 2 for an explanation of the abbreviations.

Table 2

Number of papers, considered "major highliehts in catalyst characterization" in ref. [18], that used the listed technique as the key method

\begin{tabular}{rlrc}
\hline \multicolumn{1}{c}{ Technique } & Acronym & Times used \\
\hline $1 \quad \begin{array}{l}\text { Temperature programmed reduction, } \\
\text { oxidation, desorption }\end{array}$ & TPR TPD TPD & 158 \\
2 & Infral-red spectroscopy & IR & 126 \\
3 & Chemisorption & & 74 \\
4 & Electron spin resonance & ESR & 73 \\
5 & Nuclear magnctic resunance & NMR & 68 \\
6 & Surface spectroscopies & & 56 \\
7 & Iixtcnded X-ray absorption fine structure & EXAFS & 46 \\
8 & Electron microscopy & EM & 45 \\
9 & Raman spectroscopy & & 23 \\
10 & X-ray diffraction & XRD & 18 \\
11 & Mösbauer spectroscopy & MS & 17 \\
12 & Calorimetry & & 17 \\
13 & X-ray fluorescence & XRF & 15 \\
\hline
\end{tabular}


(i) Reactions only. The concentrations of reactants and products are studied as a function of temperature, pressure, gas velocity, type of reactor, etc. The catalyst is a black box. This field comprises reaction kinetics, mechanistic studies and catalyst screening. Such studies accounted for $22 \%$ of the 250 papers presented at the 9 th ICC.

(ii) Catalyst characterization. This field represents the materials science of catalysts. Various techniques, among which Mössbauer spectroscopy, are used to study the composition and structure of catalysts. Reactions are not studied, however. Such studies accounted for $13 \%$ of the papers at the 9 th ICC.

(iii) Reactions over characterized catalysts. Results of the characterization are correlated with catalytic properties. This can be on a rather modest (such as the correlation between activity and particle size) or at a highly sophisticated level, in which techniques are used to study the catalyst in situ during reaction. Studies which combine techniques and catalytic measurements accounted for $65 \%$ of the papers at the 9 th ICC.

Hence, catalyst characterization plays a role in a large number of catalytic investigations ( $78 \%$ of the 9 th ICC papers!). It is interesting to note that the number of studies in which characterization is combined with catalytic testing is five times greater than the number dealing with characterization only!

Counting how often certain techniques have been used in the 9 th ICC papers yields the picture of fig. 9. XPS, XRD, and temperature-programmed reduction, oxidation and desorption are frequently used in catalyst characterization. Mössbauer spectroscopy, on the other hand, belongs to the techniques that are incidentally used. Of course, fig. 9 does not indicate how relevant the results from each technique are. In this respect, a recent review called "Catalyst Characterization", written by a group of nine specialists in this field, is of interest [18]. These authors reviewed the catalyst literature over a period of two years (July 1984-June 1986) and found more than 4000 papers on catalyst characterization. The authors selected about 800 papers which they considered "major highlights in catalyst characterization". Table 2 gives the number of times that a certain technique was used as the key method in those investigations. Mössbauer spectroscopy scores seventeen times, almost as often as X-ray diffraction, which according to fig. 9 is one of the most common techniques in catalyst characterization. Seventeen papers in two years which are considered highlights in the catalyst literature is certainly remarkable for a technique with limited applicability such as Mössbauer spectroscopy.

\section{Mössbauer spectroscopy in catalysis}

Applications of Mössbauer spectroscopy in catalysis are limited to one discipline of catalysis, namely catalyst characterization. For catalyst systems which contain a 
suitable Mössbauer element, the technique provides a wealth of useful and often unique information. Of course, it is a fortunate coincidence that iron and cobalt are extremely important catalytic materials, with a much more complex chemistry than noble metal catalysts.

The great advantage of Mössbauer spectroscopy is that it provides the information summarized in table 1 on catalysts under realistic conditions. One should keep in mind, however, that Mössbauer spectroscopy has one limitation in common with other in situ techniques: The most desirable information from a fundamental point of view, namely the atomic composition and structure of the catalytically active surface, cannot be obtained.

Another point which concerns the relevance of Mössbauer investigations in catalysis is the following. Both catalysis and Mössbauer spectroscopy are disciplines which demand considerable expertise. For instance, the state of a catalyst may depend critically on its method of preparation, pretreatment, or even its environment. It is therefore essential to investigate a catalyst under carefully chosen, relevant conditions and after the proper treatments. On the other hand, Mössbauer spectroscopy is not a particularly simple technique. The correct interpretation of the sometimes rather complicated spectra of highly dispersed catalysts requires a sound theoretical background in certain aspects of solid-state physics. Intensive cooperation between scientists of both fields is probably the best way to warrant meaningful and correctly interpreted results. Of course, these considerations are equally valid for other spectroscopies used in catalysis.

Finally, the author's answer to the question "How important is Mössbauer spectroscopy in catalysis?" is the following:

Mössbauer spectroscopy has given highly relevant and often unique information on a relatively small number of, however, extremely important catalyst systems.

\section{Acknowledgements}

The author thanks Dr. S. Mørup for valuable comments on parts of this manuscript. Support from a Huygens fellowship granted by the Netherlands Organization for the advancement of pure research (ZWO) is gratefully acknowledged.

\section{References}

[1] J.A. Dumesic and H. Topsoe, Adv. Catal. 26(1976)121.

[2] H. Topsøe, J.A. Dumesic and S. Mørup, in: Application of Mössbauer Spectroscopy, ed. R.L. Cohen, Vol. 2 (Academic Press, New York, 1980) p. 132.

[3] A.M. van der Kraan and J.W. Niemantsverdriet, in: Industrial Applications of the Mössbauer Effect, ed. G.J. Long and J.G. Stevens (Plenum Press, New York, 1987) p. 609. 
[4] G.A. Somorjai, Chemistry in Two Dimensions: Surfaces (Cornell University Press, Ithaca, 1981).

[5] A.M. van der Kraan, R.C.H. Nonnekens, F. Stoop and J.W. Niemantsverdriet, Appl. Catal. 27(1986)285.

[6] J.W. Niemantsverdriet, A.M. van der Kraan, W.N. Delgass and M.A. Vannice, J. Phys. Chem. 89(1985)67.

[7] S. Mørup, J.A. Dumesic and H. Topsøe, in: Application of Mössbauer Spectroscopy, ed. R.L. Cohen, Vol. 2 (Academic Press, New York, 1980) p. 1.

[8] J.W. Niemantsverdriet, A.M. van der Kraan and W.N. Delgass, J. Catal. 89(1984)138.

[9] J.W. Niemantsverdriet and A.M. van der Kraan, Surf. Interface Anal. 9(1986)221.

[10] J.W. Niemantsverdriet, J.A.C. van Kaam, C.F.J. Flipse and A.M. van der Kraan, J. Catal. 96(1985)58.

[11] F.J. Berry and S. Jobson, Hyp. Int. 41(1988)745.

[12] J.W. Niemantsverdriet, D.P. Aschenbeck, F.A. Fortunato and W.N. Delgass, J. Mol. Catal. 25(1984)285.

[13] B.S. Clausen, these Proceedings.

[14] P.H. Christensen, S. Mørup and J.W. Niemantsverdriet, J. Phys. Chem. 89(1985)4898.

[15] A.A. Hummel, A.P. Wilson and W.N. Delgass, J. Catal. (1988), in press.

[16] J.W. Niemantsverdriet and A.M. van der Kraan, J. Catal. 72(1981)385.

[17] Proc. 9th Int. Congr. on Catalysis, Calgary (1988), ed. M.J. Phillips and M. Ternan (The Chemical Institute of Canada, Ottawa, 1988).

[18] R.L. Austermann, D.R. Denley, D.W. Hart, P.B. Himelfarb, R.M. Irwin, M. Narayana, R. Szentimay, S.C. Tang and R.C. Yeates, Anal. Chem. 59(1987)68R. 